\title{
Root System Traits and Its Relationship with Photosynthesis and Productivity in Four Maize Genotypes under Drought
}

\author{
A.O. Lavinsky ${ }^{1 *}$, P.C. Magalhães ${ }^{1}$, M.M. Diniz ${ }^{1,2}$, C.C. Gomes-JR ${ }^{1,2}$, \\ E.M. CASTRO ${ }^{3}$ and R. ÁvILA ${ }^{3}$ \\ ${ }^{1}$ Embrapa Milho e Sorgo, Rodovia MG-424, Km 45 Caixa Postal: 285 ou 151 CEP: 35701-970, \\ Sete Lagoas, MG, Brazil \\ ${ }^{2}$ Universidade Federal de São João Del Rey, CEP 35701-970 Sete Lagoas, MG, Brazil \\ ${ }^{3}$ Universidade Federal de Lavras, CEP 37200-000, Lavras, MG, Brazil
}

(Received 19 January 2015; Accepted 24 February 2015;

Communicated by J. Johnson)

\begin{abstract}
The present study combined evaluations of agronomic parameters such as roots morphometry (using the WinRhizo program) and leaf gas exchange, in order to detect features in the root system which allow the maintenance of photosynthetic rates and productivity in four maize genotypes contrasting for tolerance to water deficit (WD), two tolerant (DKB 390 and BRS1055) and two sensitive (BRS 1010 and 2B710). The genotypes showed similar tolerance to dehydration of leaf tissue, but the tolerant genotypes DKB 390 and BRS1055 presented higher photosynthetic rate and yield compared to the sensitive BRS 1010 and 2B710. Nevertheless, divergent strategies of adaptation to drought among tolerant genotypes were observed. The genotype DKB 390 presented physiological mechanisms in shoots responsible for minimizing water loss, which decreases the dependence of root adjustments to increase the absorption of water. In turn, the BRS 1055 genotype showed a drought avoidance strategy by producing fine roots associated with a higher leaf area.
\end{abstract}

Keywords: WinRhizo, leaf gas exchange, photoassimilate, root

\section{Introduction}

The threat of global climate changes has caused concern in agriculture, since climatic factors essential for the development of crops will be severely affected, reducing the production and quality of food (IPCC 2007). Since most of the crops are produced in tropical regions, characterized by low water availability and the occurrence of more frequent and severe dry seasons (Easterling et al. 2007; Tubiello and Fischer 2007), researches are needed to identify the adaptive priority for investment in agriculture (Lobell et al. 2008), because in these regions live many families who depend on agriculture as the only means of survival (Haile 2005). These adjustments will reduce the severity of the predicted impacts on crop production in tropical regions, among which maize (Zea mays L.).

Maize is an important cereal for human and animal feed, and the severe water deficit observed in Brazil has reduced the production and supply of this grain, affecting mainly

*Corresponding author; E-mail: alynelavinsky@gmail.com; Phone: +55 3130271147 
rural farmers and small agro-industries in the Northeast that use maize in animal feeding (Gutierrez et al. 2014). The main objectives of selection for increasing productivity in maize include stay green, anthesis-silking interval and the number of ears per plant, advantageous characteristics under water deficit (WD). Thus, studies for phenotypic characterization and on productivity of maize genotypes under WD are the initial steps to elucidate the possible mechanisms involved in the physiological differential behavior of some maize genotypes under this stress condition, and to provide subsidies for selection to drought tolerance. In this context, the search for new descriptors that reflect productivity, such as the characterization of roots via the "WinRhizo" software (Magalhães et al. 2011) is very important.

According to the theory of functional balance (Brouwer 1962) plants increase the allocation of biomass to shoots if the carbon gain is affected by limiting resources above ground, as light and $\mathrm{CO}_{2}$. Similarly, the plants increase the biomass allocation to the roots when subjected to low levels of underground resources, i.e. water and nutrients (Poorter and Nagel 2000). Although the flexibility of biomass allocation to this organ of capture and storage of resources constitute a key point in the determination of physiological changes in plants in environments with low water availability in the soil (Davies and Zhang 1991), little is known about this relationship (Fort et al. 2012). The relationship between the carbon allocation and water economy has been studied mainly in organs located above ground, with particular emphasis on the leaves.

As under WD the adaptive strategies in organs located below ground overlap those above ground (Fort et al. 2012), and there is variation in the different traits of the same species (Liu et al. 2010), more investment in root system possibly increase the absorption of water in the soil, maintaining photosynthetic activity and productivity. This study combined evaluation of agronomic traits with root morphometry using the program WinRhizo and leaf gas exchange in order to identify the root system characteristics allowing the maintenance of photosynthetic rate and the productivity of four maize genotypes under WD.

\section{Materials and Methods}

\section{Cultivation, plant material and experimental design}

The experiment was conducted in a greenhouse at National Maize and Sorghum Research Center (19 $28^{\prime}$ 'S, $44^{\circ} 15^{\prime} 08^{\prime}$ ' $\mathrm{W}, 732 \mathrm{~m}$ altitude), and the plant material consisted of four maize hybrids contrasting for drought tolerance, two tolerant (DKB 390 and BRS1055) and two sensitive (BRS 1010 and 2B710).

Plants were grown in plastic pots with 20 liter capacity, containing typical dystrophic Red Latosol soil. The water content in the soil was daily monitored between 09:00 a.m. and 03:00 p.m., with moisture sensors model GB Reader N1535 (Measurement Engineering, Australia) installed in the center of each pot with the aid of a screw auger, to a depth of $20 \mathrm{~cm}$. These sensors detect the water supply in the soil based on electrical resistance and are coupled to digital meters. Water replacement by irrigation was based on the data obtained with the sensor and water was added up to field capacity during the period pre- 
ceding the imposition of the treatments. The water replacement calculations were performed with the aid of a spreadsheet, based on soil water retention curve. In parallel, all cultural and phytosanitary treatments required were performed.

At the pre-flowering stage, half of each initial treatment was subjected to water deficit (WD); the other half continued to receive daily irrigation in order to maintain soil moisture close to field capacity (FC), with soil water tension of $-18 \mathrm{kPa}$. Water deficit occurred by daily providing $50 \%$ of the total available water until soil water tension reaches at least $-138 \mathrm{kPa}$. After twelve days under this condition, the leaf water potential was determined with a pressure pump type Scholander at noon $\left(\Psi_{\mathrm{md}}\right)$. Leaf gas exchange and the fluorescence of chlorophyll $a$ were measured with an infrared gas analyzer (IRGA - Infrared Gas Analyzer) Model 6400 LI (LI-COR, Lincoln, NE, USA) equipped with a fluorometer (LI-6400-40, LI-COR Inc.), in leaves corresponding to the ear insertion. Then, the water supply was restored and maintained at optimum levels by the end of the cycle. At harvest, the agronomic parameters associated with productivity were analyzed according to the methodology detailed in the "agronomic parameters" section. The experimental unit was the pot containing two plants, with six replications per treatment.

Preliminary statistical tests were applied to adjust or not the results of analysis of variance (ANOVA). The Scott-Knott test at 5\% probability was used to test any contrast.

\section{Agronomic parameters}

Leaf number, ear number, leaf area, plant height, ear insertion height (measured using a graduated ruler and/or packimeter), diameter and length of the ear were quantified. Leaf area was measured with an area meter (Li-Cor Inc.). Then the plants were partitioned into root, stem, leaves, tassel, ears (cob, straw and grains), and dried in an oven with forced air circulation at $70{ }^{\circ} \mathrm{C}$ for $72 \mathrm{~h}$. Based on the dry weight value obtained for each of the different parts, the harvest index was estimated. In addition, number of grains per ear and weight of 100 grains were estimated.

Additionally, a group of 50 grains was subjected to morphometric characterization, measuring the dimensions of the grains (length, width and thickness) using a digital packimeter, with three replications per treatment. Subsequently, these grains were soaked overnight in ethylenediamine $(10 \%, \mathrm{w} / \mathrm{v})$ and longitudinally cut by a knife to evaluate possible changes in embryo size, depending on the treatment. Photographs were obtained using a stereoscopic microscope and the ImageJ program was used to calculate the ratio between the areas of the endosperm and the embryo.

For the evaluation of the root system the computerized system WinRhizo Pro 2007a (Regent Inc. Instr.) was used, measuring length, diameter, volume and surface area of roots by diameter class, as follows: very fine roots $(\varnothing$ less than $0.5 \mathrm{~mm}$ ), fine roots $(>0.5 \varnothing<2.0 \mathrm{~mm})$ and thick roots $(\varnothing>2.0 \mathrm{~mm})$ (Magalhães et al. 2011). For this analysis, roots were collected in three replications per treatment. 


\section{Results}

At the end of the water stress period, all maize genotypes under water deficit (WD) showed negative values of leaf water potential at midday $\left(\Psi_{\mathrm{md}}\right)$ compared to the plants maintained in soil moisture at field capacity (FC); however, it was not possible to distinguish sensitive and tolerant genotypes based on this variable (data not shown).

Under field capacity, the value of photosynthetic rate $(A)$ and stomatal conductance to water vapor $\left(g_{\mathrm{s}}\right)$ were different among genotypes, with higher values for BRS 1055, intermediate for 2B710 and DKB 390, and lower for BRS1010. Even in this condition, the transpiration rate values $(E)$ were higher for genotype 2B710 intermediate for BRS 1055 , and smaller in BRS 1010 and DKB 390, and the internal concentration of carbon $\left(C_{\mathrm{i}}\right)$ unchanged (Table $\mathrm{S} 1 *$ ).

In turn, irrespective of genotype, a significant reduction existed of $A, F v F m$ and $g_{\mathrm{s}}$ in plants exposed to the stress caused by WD compared to those who had the soil moisture maintained close to FC, along with an increase in $C_{\mathrm{i}}$ values (Table S1). Plants of the tolerant genotypes (DKB390 and BRS1055) showed on average values of $A$ and $g_{\mathrm{s}} 70.33 \%$ and $64.66 \%$ higher under WD, respectively, compared to the susceptible genotypes (2B710 and BRS1010) grown in the same condition. In addition, sensitive genotypes presented lower transpiration rates $(E)$ compared to tolerant. However, as the $A$ values for BRS 1010 under WD was very low, water use efficiency ratio $(A / E)$ was also low. In the genotype 2B710 water deficit decreased the gradient required to ensure adequate diffusion of $\mathrm{CO}_{2}$ from the atmosphere to the carboxylation site at the chloroplast in lower level than BRS1010 and $A / E$ did not reduce, maintaining values similar to those observed in tolerant genotypes, besides a lower volume of water in the soil.

In plants from the BRS 1055 under WD high values of $A$ did not produce higher grain yield. Plants from genotypes 2B710 and DKB 390, with the soil moisture kept close to FC throughout the phenological cycle showed higher grain biomass (GB) and ear diameter (ED) compared to BRS 1010 and BRS 1055, without change in plant height (PH), ear insertion height (EIH), specific leaf area (SLA), individual leaf area (ILA), leaf number (LN), and total biomass (TB). As a result, the harvest index (HI) was on average $14.2 \%$ higher in genotypes 2B710 and DKB 390 compared to BRS 1010 and BRS 1055 (Table S2). DKB 390 plants under FC had lower ear length (EL) without change in the number of grains per row (NGR), and yet, the weight of 100 grains (W100G) was higher than in the other genotypes. In turn, in 2B710 plants under FC the higher GB was associated with a greater number of grains per ear (NGE), with values similar to those observed in BRS 1055 plants (Table S2).

Under water deficit the DKB 390 maintained HI significantly higher compared to the other genotypes, which is associated with higher NGE and EL. Plants of genotype 2B710 under WD presented HI highly reduced compared to the plants maintained at field capacity, with values similar to the observed for BRS 1010 and BRS 1055 (Table S2), corroborating the decrease in grain size and NGE, without alteration in P100 under WD.

*Further details about the Electronic Supplementary Material (ESM) can be found at the end of the article. 
Regardless of the water content in the soil, plants of BRS 1055 genotype presented GB superior to the DKB 390, BRS 1010 and 2B710, which explains the lower HI compared to the DKB 390. However, significant decrease was not observed for HI and LA for this genotype exposed to water stress.

Only plants of BRS 1010 and 2B710 showed values considerably reduced for LA under WD causing lower values of GB, ED and HI. In fact, only the susceptible plants from BRS1010 and 2B710 presented area of embryo in relation to the endosperm (EM:E) reduced under WD and a decrease in GB compared to FC indicating the occurrence of a low photoassimilate flow to the grain in these two maize genotypes under WD, compared to genotypes DKB 390 and BRS 1055. In turn, the values of EM:E in plants of tolerant genotypes DKB 390 and BRS 1055 under WD did not vary in relation to these plants at FC, confirming the continuity of the flow of photoassimilates to embryo nourishment.

Morphometric analysis of images of roots previously scanned using the program WinRhizo showed no difference between genotypes at field capacity regarding length, surface area and volume in the different classes of diameter (Table S3). However, under the water deficit the BRS1055 genotype showed higher fine root length (FRL), surface area of fine roots (SAFR), total surface area of roots (TSAR) and volume of fine roots (VFR) compared with other genotypes (Table S3). In addition, plants from this genotype under WD had FRL, surface area of very fine roots (SAVFR), SAFR, total root surface area (TRSA) and FRV greatly increased compared to those kept under field capacity, while in the genotypes BRS 1010 and DKB 390 these variables did not change. For the sensitive genotype 2B710 under water deficit SAVFR, SAFR and TSAR decreased compared to the plants of the same genotype under FC (Table S3).

\section{Discussion}

In conditions of low soil water availability, a decrease occurs in $\Psi_{\text {md }}$ leading to water deficit (Souza et al. 2013). One of the earliest responses to WD is stomatal closure, which limits the leaf gas exchange and therefore productivity (Mutava et al. 2011). Assessing the $\Psi_{\mathrm{md}}$ at the end of the drought imposition period in maize genotypes grown under WD, Vitale et al. (2007) and Souza et al. (2013) found a reduced $\Psi_{\text {md }}$ compared to their respective controls under FC. Souza et al. (2013) also observed a differential maintenance of water status under WD, depending on the degree of tolerance of the genotype to WD, with higher values in tolerant genotypes than in sensitive ones. In this study, all genotypes showed similar tolerance to leaf dehydration, with reduced $\Psi_{\mathrm{md}}$ values under WD. However, the genotypes BRS DKB 390 and 1055 under WD presented greater values of $A$ and gs compared to BRS 1010 and 2B710, and also larger values of $E$.

Notably, under water deficit the BRS 1010 genotype scarcely lost latent heat via $E$, and thus probably the leaf temperature was increased, causing damage in the photochemical step of photosynthesis. With photochemical damage, NADPH and ATP to be used by the enzymes of reduction and phosphorylation of carbon in the biochemical step was impaired, thereby explaining the increase in $C_{\mathrm{i}}$ and the very low values of $A$ compared to the plants of this genotype under FC. The low values of $A$, associated with low values of $E$ 
resulted in lower $A / E$. Note that the BRS1010 genotype presented under WD, $A$ values 7.81 times lower compared to $2 \mathrm{~B} 710$ while $E$ was only 2.18 times lower, which explains the values of $A / E$ in $2 \mathrm{~B} 710$ similar to those in DKB 390 and BRS 1055. According to Mutava et al. (2011), the genotypes tolerant to WD remain productive by increasing $E$ which, in turn, occurs at the expense of increased water consumption. By releasing more water via the stomata opening, there would be a leaf cooling, which would prevent photochemical damage. However, all genotypes had $F v F m$ decreased under WD compared to their respective controls, in FC, and the BRS 1055 showed larger values of this variable under WD, compared to the other.

The genotype BRS 1055 under field capacity presented an increase of $21 \%$ in $A$, consequently increasing 7.6\% the TDB and decreasing 9.8\% DGB compared to the DKB 390 genotype in the same condition. Considering that these two genotypes showed similar tolerance to WD, it was expected that higher $A$ values would result in higher grain productivity. Long et al. (2006) found that higher productivity is not Always associated to higher values of $A$ and there is a great contribution of characteristics genetically controlled. In fact, Magalhães and Jones (1990) observed that the grain size and the potential to accumulate photoassimilates in maize are probably determined by the number and size of the endosperm cells. Thus, it is possible that in the BRS 1055 under FC the largest $A$ do not result in greater DGB because the cells that accumulate photoassimilates were already completely filled. In addition, the metabolic costs associated with the highest DRB in BRS 1055 compared to the other genotypes overlapped the gains coming from $A$, thus impairing productivity.

Under WD, the genotypes DKB 390 and BRS 1055 showed similar values of $A$ and TDB, but the DGB was 28\% higher in the DKB 390, resulting in higher $\mathrm{HI}$ in relation to BRS 1055. The lower HI values in BRS 1055 would be interpreted as a low tolerance for WD. However, when compared to the control (under FC) a decrease of only $9.3 \%$ occurred in HI for BRS 1055 under WD. The sensitive genotypes BRS 1010 and 2B710 under WD presented reductions of 22 and $24 \%$ respectively at the end of the drought imposition period. The plants from the BRS 1055 genotype have a constitutively higher capacity of the source per se, associated with a root system specialized in water absorption, thus large reductions in $A$ had little effect on the availability of photoassimilates in the source under WD, and thus the flow of photoassimilates from source organs to drain organs (such as grain filling) was similar to the plants under FC.

Souza et al. (2013) reported that the largest HI of DKB 390 genotype under WD was not correlated only to shoot features, but also to increases in the formation of aerenchyma in the cortex and in the thickness of exoderm of roots. In addition, a higher number of metaxylem elements with a smaller diameter, which in turn may indicate a high hydraulic conductivity of root, increasing the water transport capacity of the vessel in the phloem (Li et al. 2009). According to Zhu et al. (2010) increases in the formation of aerenchyma in the root cortex help the axial growth of roots, through the decrease of cells in respiration in this tissue. In contrast, under WD no significant variations were observed in adjustments of growth, surface area and volume in root plants of DKB 390 from all the different classes of diameter evaluated. Thus, the increase in the amount of aerenchyma 
was used only for the maintenance of the physiological processes in the root, which although beneficial, does not improve the water capture in this genotype. In this case, as the DKB 390 genotype under WD did not use mechanisms to increase the absorption of water, each leaf area unit had less non-photosynthetic tissue to sustain, which allowed the maintenance of productivity even under stress.

Few studies have examined how the root traits are related to the photosynthetic rate and yield in plants grown under WD (Souza et al. 2013; Uga et al. 2013; Horta et al. 2014). Uga et al. (2013) showed that by altering its structure to increase the angle of root growth, plants using drought avoidance strategy could exploit water into deeper layers of the soil, allowing significant improvement in the photosynthetic rate and the grain yield by maintaining influx pressure of sucrose through the plasmodesmata in the phloem into sink cells (Edmeades et al. 2000). Only BRS 1055 plants presented increases in FRL under WD, without significant changes in the DRB. Note that the largest amount of water absorbed by the root system comes from fine and very fine roots, and only plants with conservative characteristics of arid environments present improvement in water absorption efficiency for producing very fine roots (Liu et al. 2010).

Roots of the genotype 2B710 under WD presented a substantial reduction in SAVFR, SAFR and TSAR. Considering that the root cap acts on the geotropism and protects the root meristem from damages due to a mucilage secretion at the edge of the cells (Iijima et al. 2004), it is possible that under WD the area of these roots have been reduced leaving the meristem unprotected. As a result, there was a smaller replacement of the damaged cells of the root cap by the quiescent center, which led to a restriction in the surface area of the roots of this genotype, without affecting the RDB.

BRS 1055 under FC, unlike DKB 390, BRS 1010 and 2B710, showed no positive linear response for the relationship between $A$ and productivity. Possibly, the cell for accumulation of photoassimilates are controlled by genetic factors, and thus the saturation of the grain capacity does not require so high $A$ values; in addition, increased investment in non-photosynthetic structures (roots), may have diverted resources that would be used by filling grains on that particular genotype.

DKB 390 and BRS1055 genotypes are more tolerant to WD than BRS 1010 and 2B710. However, the results showed that these two tolerant genotypes have different mechanisms to overcome the stress generated by the WD. DKB 390 uses mainly physiological mechanisms at shoot level for the maintenance of productivity, by minimizing water loss, which decreases the dependence of adjustments in the root system to increase the absorption of water, while BRS 1055 present a strategy for avoiding drought producing fine roots, in parallel to a higher LA.

\section{References}

Brouwer, R. 1962. Distribution of dry matter in the plant. Netherlands J. of Agric. Sci. 10:399-408.

Davies, W.J., Zhang, J. 1991. Root signals and the regulation of growth and development of plants in drying soil. Annu. Rev. Plant Physiol. and Plant Mol. Biol. 42:55-76.

Easterling,W.E., Aggarwal, P.K., Batima, P. Brander, L.M., Erda, L., Howden, S.M. 2007. Food, fiber and forest products. In: Parry, M.L., Canziani, O.F., Palutikof, J.P., Van der Linden, P.J., Hanson, C.E. (eds.), 
Climate Change 2007: Impacts, Adaptation and Vulnerability. Contribution of working group II to the fourth assessment report of the Intergovernmental Panel on Climate Change. Cambridge University Press. Cambridge, UK. pp. 273-313.

Edmeades, G.O., Bolanos, J., Elinge, A., Ribaut, J-M., Baenziger, M., Westgate, M.E. 2000. The role and regulation of the anthesis-silking interval in maize. In: Westgate, M.E., Boote, K.J. (eds), Physiology and Modeling Kernel Set in Maize. CSSAO. Madison, Wisconsin, USA. pp. 43-73.

Fort, F., Jouany, C., Cruz, P. 2012. Root and leaf functional trait relations in Poaceae species: implications of differing resource-acquisition strategies. J. of Plant Ecol. 2:1-9.

Gutierrez, A.P., Engle, N.L., Nys, E.D., Molejón, C., Martins, E.S. 2014. Drought preparedness in Brazil. Weather and Climate Extremes 3:95-106.

Haile, M. 2005. Weather patterns, food security and humanitarian response in sub-Saharan Africa. Philosophical Transactions of the Royal Society of London 360:2169-2182,

Horta, L.P., Braga, M.R., Lemos-Filho, J.P., Modolo, L.V. 2014. Organ-coordinated response of early-postgermination mahogany seedlings to drought. Tree Physiol. 34:1-12.

Iijima, M., Higuchi, T., Barlow, P.H. 2004. Contribution of root cap mucilage and presence of an intact root cap in maize (Zea mays) to the reduction of soil mechanical impedance. Ann. Bot. 94:473-477.

IPCC. Summary for policymakers. 2007. In: Solomon, S., Qin, D., Manning, M., Chen, Z., Marquis, M., Averyt, K.B., Tignor, M., Miller, H.L. (eds). Climate change 2007: The physical Science Basis. Contribution of working group I to the fourth assessment report of the Intergovernmental Panel on Climate Change. Cambridge University Press. Cambridge, UK and New York, USA. pp. 1-18.

Li, Y., Sperry, J.S., Shao, M. 2009. Hydraulic conductance and vulnerability to cavitation in corn (Zea mays L.) hybrids of differing drought resistance. Environmental and Exp. Bot. 66: 341-346.

Liu, G., Frescher, G.T., Pan, X., Cornelissen, J.H.C., Li, Y., Dong, M. 2010. Coordinated variation in leaf and root traits across multiple spatial scales in Chinese semi-arid and arid ecosystems. New Phytologyst 188:543-553.

Lobell, D.B., Burke, M.B., Tebaldi, C., Mastrandrea, M.D., Falcon, W.P., Naylor, R.L. 2008. Prioritizing climate change adaptation needs for food security in 2030. Science 319:607-610.

Long, S.P., Zhu, X.G., Naidu, S.L., Ort, D.R. 2006. Can improvement in photosynthesis increase crop yields? Plant Cell Environ. 29:315-330.

Magalhães, P.C., Jones, R. 1990. Aumento de fotoassimilados na taxa de crescimento e peso final dos grãos de milho (Photoassimilate increase on growth rate and final grain weight in maize). Pesquisa Agropecuária Brasileira 25:1747-1754. (in Portuguese)

Magalhães, P.C., Souza, T.C., Cantão, F.R.O. 2011. Early evaluation of root morphology of maize genotypes under phosphorus deficiency. Plant Soil Environ. 57:135-138.

Mutava, R.N., Prasad, P.V.V., Tuinstra, M.R., Kofoid, K.D., Yu, J. 2011. Characterization of sorghum genotypes for traits related to drought tolerance. Field Crop Res. 123:10-18.

Poorter, H., Nagel, O. 2000. The role of biomass allocation in the growth responses of plants to different levels of light, $\mathrm{CO}_{2}$ and water: a quantitative review. Aust. J. of Plant Physiol. 27:595-607.

Souza, T.C., Castro, E.M., Magalhães, P.C., Lino, L.O. Alves, E. T.; Albuquerque, P. 2013. Morphophysiology, morphoanatomy, and grain yield under field conditions for two maize hybrids with contrasting response to drought stress. Acta Physiologiae Plantarum 35:3201-3211.

Tubiello, T.N., Fischer, G. 2007. Reducing climate change impacts on agriculture: Global and regional effects of mitigation 2000-2080. Technol. Forecasting and Social Change 74:1030-1056.

Uga, Y., Sugimoto, K., Satoshi Ogawa, S., Rane, J., Ishitani, M., Hara, N., Kitomi, Y., Inukai, Y., Ono, K., Kanno, N., Inoue, H., Takehisa, H., Motoyama, R., Nagamura, Y., Wu, J., Matsumoto, T., Takai, T., Okuno, K., Yano, M. 2013. Control of root system architecture by DEEPER ROOTING 1 increases rice yield under drought conditions. Nature Genetics 45:1097-1105.

Vitale, L., Di Tommasi, P., Arena, C., Fierro, A., De Santo, V.A., Magliulo, V. 2007. Effects of water stress on gas exchange of field grown Zea mays L. in Southern Italy: An analysis at canopy and leaf level. Acta Physiologia Plantarum 29:317-326.

Zhu, J., Brown, K.M., Lynch, J.P. 2010. Root cortical aerenchyma improves the drought tolerance of maize (Zea mays L.). Plant Cell Environ. 33:740-749. 


\section{Electronic Supplementary Material (ESM)}

Electronic Supplementary Material (ESM) associated with this article can be found at the website of CRC at http://www.akademiai.com/content/120427/

Electronic Supplementary Table S1. Gas exchange parameters obtained in four maize genotypes with contrasting tolerance to drought (BRS1010 and 2B710 - sensitive; DKB390 and BRS1055 - tolerant) grown under different water levels in the soil (field capacity - FC, and water deficit - WD)

Electronic Supplementary Table S2. Agronomic production in four maize genotypes with contrasting characteristics for drought tolerance (BRS1010 and 2B710 - sensitive; DKB390 and BRS1055 - tolerant) grown under different water contents in the soil (field capacity - FC, and water deficit - WD)

Electronic Supplementary Table S3. Morphometric characterization of roots in four maize genotypes with contrasting characteristics for drought tolerance (BRS1010 and 2B710 - sensitive; DKB390 and BRS1055 tolerant) grown under different water levels in the soil (field capacity - FC, and water deficit - WD) 